\title{
ANATOMIA DA MADEIRA E DESCRIÇÃO MORFOLÓGICA DE SCUTIA BUXIFOLIA REISSEK (RHAMNACEAE) ${ }^{1}$
}

\author{
SIDINEI RODRIGUES DOS SANTOS ${ }^{2}$ JOSÉ NEWTON CARDOSO MARCHIORI ${ }^{3}$ THAIS SCOTTI DO \\ CANTO-DOROW ${ }^{4}$
}

\section{RESUMO}

O presente trabalho trata da anatomia da madeira e descrição morfológica de Scutia buxifolia Reissek (Rhamnaceae), com base em material proveniente do Rio Grande do Sul, Brasil. A estrutura anatômica concorda, em linhas gerais, com o referido na literatura para a família Rhamnaceae e gênero Scutia: poros solitários e em múltiplos radiais, de contorno oval e com abundante conteúdo no cerne; pontoações intervasculares muito pequenas; parênquima paratraqueal associado a apotraqueal marginal; raios heterogêneos tipo II, com cristais abundantes; e fibras libriformes muito curtas e de paredes espessas. A madeira reúne características anatômicas xeromórficas e evoluídas. A composição microscópica do lenho justifica a excelente qualidade atribuída à madeira (homogênea, dura, pesada e resistente a deterioração).

Palavras-chave: Scutia buxifolia, anatomia da madeira, Rhamnaceae, coronilha.

\section{ABSTRACT}

[Wood anatomy and morphological description of Scutia buxifolia Reissek (Rhamanaceae)].

The wood anatomy and morphological description of Scutia buxifolia Reissek (Rhamnaceae) are described, based on materials from Rio Grande do Sul state, Brazil. The anatomical structure agrees with literature references to family Rhamnaceae and genus Scutia: solitary pores, in radial multiples, with oval outline and abundant contents in the heartwood; very small intervessel pits; paratracheal parenchyma associated with marginal apotracheal; heterogeneous II rays, with abundant crystals; and very short libriform fibres, with thick walls. The anatomical structure shows both xeromorphic and high-developed characteristics. The microscopic composition justifies the excellent quality attributed to the wood (homogeneous, hard, heavy and resistant to deterioration).

Key words: Scutia buxifolia, wood anatomy, Rhamnaceae, coronilha.

\section{INTRODUÇÃO}

Pertencente a família Rhamnaceae, Scutia buxifolia Reissek, a popular coronilha, é arbusto espinhoso muito ramificado ou árvore pequena (raramente de grande porte), de tronco tortuoso, ramos finos e espinhos esparsos (Johnston \& Soares, 1972). Espécie mais conhecida de sua família botânica no Rio Grande do Sul, a coronilha apresenta ampla distribuição no Estado, ocorrendo tanto em solos úmidos, compactados ou paludosos, como em solos secos, sobretudo na orla ou interior de matas com araucária, em pequenos capões de áreas campestres, em matas ciliares ou como árvores isoladas em pleno campo (Bastos, 1989).

Segundo Tortosa (1995), a espécie ocorre desde o Uruguai e sudeste do Brasil (sul, de acordo com Johnston e Soares, 1972), até o norte da Argentina, Paraguai e Bolívia. No Brasil, sua ocorrência é assinalada para o Paraná, Santa

1 Recebido para publicação em 10/05/2008 e aceito para publicação em 20/06/2008.

2 Biólogo, bolsista do CNPq - Brasil, mestrando do Programa de Pós-Graduação em Engenharia Florestal, Departamento de Ciências Florestais, Universidade Federal de Santa Maria, CEP 97105-900, Santa Maria, RS, Brasil. sthurt.bio@gmail.com

3 Engenheiro Florestal, Dr., bolsista de Produtividade em Pesquisa do CNPq, professor Titular do Departamento de Ciências Florestais, Universidade Federal de Santa Maria, Santa Maria, RS, Brasil.

${ }^{4}$ Bióloga, Dra., professora do Departamento de Biologia, Universidade Federal de Santa Maria, RS, Brasil. 
Catarina e Rio Grande do Sul, sendo a única espécie do gênero neste Estado. O gênero Scutia (Comm. ex A. DC.) Brongn. compreende umas 5 espécies, quatro delas sul-americanas, e uma da África e Ásia. O Brasil conta com duas espécies: Scutia buxifolia Reissek e Scutia arenicola (Casaretto) Reissek.

A madeira de Scutia buxifolia, de cor avermelhada ou violácea, é elástica e homogênea, dura, pesada (peso específico superior a $1,0 \mathrm{~g} / \mathrm{cm}^{3}$ ) e tida como incorruptível, sobretudo o cerne. Apesar da excelente qualidade, apresenta forte tendência a rachar-se com a secagem. Adequada para obras externas, esteios e tornearia, desde que as dimensões do tronco o permitam, serve, igualmente, para lenha e carvão, tendo ótimo poder calorífico (Marzocca \& Marthi, 1951; Corrêa, 1926). Chama atenção, portanto, as escassas referências anatômicas sobre a madeira desta espécie, fato que pode ser atribuído à dimensão geralmente reduzida dos troncos.

A escassez de referências anatômicas, aliás, é aspecto comum em Rhamnaceae, salientando-se, a este respeito, os trabalhos de Record \& Hess (1949) e Metcalfe \& Chalk (1972). Para o gênero Scutia, Metcalfe \& Chalk (1972) destacam: elementos vasculares com placas de perfuração simples, espessamentos espiralados e pontoações intervasculares alternas, pequenas a diminutas; parênquima axial em faixas terminais, uni a bisseriadas; raios de até $1,5 \mathrm{~mm}$ em altura, com abundantes cristais de oxalato de cálcio; e fibras de paredes espessas a muito espessas, com pontoações simples.

O presente trabalho, que trata da caracterização microscópica do lenho e descrição morfológica de Scutia buxifolia, visa a oferecer subsídios para o melhor aproveitamento de sua madeira, bem como contribuir para o conhecimento da estrutura anatômica e morfologia das Rhamnaceae sul-brasileiras.

\section{MATERIAL E MÉTODOS}

Para a descrição morfológica foram examinadas exsicatas botânicas provenientes de di- versos herbários do Rio Grande do Sul: HDCF (Herbário do Departamento de Ciências Florestais, Universidade Federal de Santa Maria), PEL (Herbário do Departamento de Botânica, Universidade Federal de Pelotas), PACA (Herbarium Anchieta, Unisinos, São Leopoldo) e SMDB (Herbário do Departamento de Biologia, Universidade Federal de Santa Maria).

A descrição anatômica baseou-se no estudo de duas amostras de madeira, conservadas na xiloteca do Departamento de Ciências Florestais da Universidade Federal de Santa Maria, com os seguintes registros:

- Santana da Boa Vista, BR-392, em mata com araucária, na beira da estrada; arvoreta ca. 2,5m, com frutos, J. N. C. Marchiori s.n., 4.V.2007 (HDCF 5731).

- São Vicente do Sul, mata ciliar do rio Ibicuí; J. N. C. Marchiori s.n., 17.IV.1981 (HDCF 176).

Para a descrição da madeira, foram preparadas lâminas de cortes anatômicos e de macerado. Do material lenhoso, foram extraídos três corpos de prova $(2 \times 2 \times 3 \mathrm{~cm})$ da parte mais externa do lenho, próximo ao câmbio, orientados para obtenção de cortes anatômicos nos planos transversal, longitudinal radial e longitudinal tangencial. Um outro bloco foi também retirado, com vistas à maceração. Para as lâminas de cortes anatômicos, seguiu-se a técnica padrão no Laboratório de Anatomia da Madeira da Universidade Federal do Paraná: as amostras foram amolecidas por fervura em água e seccionadas em micrótomo de deslizamento, regulado para a obtenção de cortes com espessura nominal de $20 \mu \mathrm{m}$. Os cortes foram tingidos com acridina-vermelha, crisoidina e azul-deastra (Dujardin, 1964), desidratados em série alcoólica-ascendente (30\%, 50\%, 70\%, 95\% e duas vezes em álcool absoluto), diafanizados em xilol e montados em lâminas permanentes, usando-se "Entellan" como meio de montagem. Para a confecção de lâminas de macerado, utilizouse o método de Jeffrey (Burger \& Richter, 1991), sendo a pasta resultante colorida com solução aquosa de safranina $1 \%$. A montagem das lâminas seguiu o método anteriormente des- 
crito, com a diferença de que as três primeiras etapas foram desenvolvidas sobre papel de filtro. Para as lâminas de macerado de um dos indivíduos (HDCF 5731), seguiu-se o procedimento de Franklin (1945), modificado (Kraus \& Arduin, 1997).

A descrição microscópica da madeira seguiu as recomendações da Copant (1973). Os valores quantitativos são resultantes de 30 medições, com exceção da percentagem dos tipos celulares e das classes de raio, para as quais foram realizadas 600 determinações ao acaso, usando-se contador de laboratório. A freqüência de poros $/ \mathrm{mm}^{2}$ foi obtida de forma indireta, a partir de um quadrado vazado de área conhecida, superposto a fotomicrografias de seção transversal. As medições foram realizadas em microscópio binocular Carl Zeiss, provido de ocular com escala graduada.

As fotomicrografias foram tomadas em microscópio Olympus cx40, equipado com câmera digital Olympus Camedia c3000.

A terminologia utilizada para a descrição morfológica seguiu Radford et al. (1974). A análise das estruturas foi realizada em lupa binocular Olympus SZ40, com régua de precisão $(0,5 \mathrm{~mm})$ e papel milimetrado. Informações relativas ao porte, floração, frutificação, distribuição geográfica, coloração e consistência de estruturas, foram obtidas a partir de observações a campo e de anotações contidas nas etiquetas de identificação das exsicatas.

\section{DESCRIÇÃO MORFOLÓGICA}

Scutia buxifolia Reissek S. Reissek, in Martius, Fl. Bras. 11(1):93. 1861.

Arbustos ou arvoretas de até $7 \mathrm{~m}$ de altura, ramosos, glabros, armados; tronco de pequenas dimensões; casca branca ou escuro-acinzentada, geralmente com deiscência em pequenas placas irregulares até retangulares, que se desprendem pelas extremidades, expondo a periderme adjacente marrom-avermelhada. Ramos jovens verdes ou castanhos, floríferos, folhosos, subopostos ou opostos, ascendentes até verticais, lisos, flexíveis e de dois tipos: longos, cilín- dricos a ligeiramente angulosos e geralmente armados, ou então curtos (raramente longos e pendentes), finos, angulosos e geralmente inermes; ramos antigos cilíndricos, robustos, ásperos, acinzentados, geralmente armados (Figura 1a,b,c). Espinhos de até $6,4 \mathrm{~cm}$ de comprimento, vigorosos, cônicos, retos, de extremidade quase sempre escurecida, divaricados até horizontais e geralmente em disposição cruzada, por vezes canaliculados (Figura 1a). Folhas verdes, simples, pequenas, curto-pecioladas, persistentes, subopostas ou alternas, coriáceas e brilhantes, especialmente quando jovens; limbo finamente reticulado, elíptico, menos freqüentemente ovado ou obovado, ocasionalmente quase circular, inteiro ou obscuramente serrilhado na metade superior, raro inteiramente serrilhado, medindo 0,9 $6,8 \mathrm{~cm}$ de comprimento por $0,5-3,3 \mathrm{~cm}$ de largura; margem esbranquiçada na face abaxial, em material seco; ápice geralmente mucronado, retuso, menos freqüentemente arredondado ou acuminado; base estreitamente cuneada ou menos freqüentemente arredondada; nervuras braquidódromas: a principal, proeminente, vistosa; as demais, finas e pouco evidentes (Figura 1a). Pecíolos de até $3 \mathrm{~mm}$ de comprimento. Estípulas foliares subuladas, pareadas, caducas, geralmente do mesmo tamanho ou menores do que o pecíolo; estípulas florais, diminutas. Flores numerosas, perfeitas, períginas, pentâmeras, de simetria radial, glabras, esverdeadas, pequenas (2,5-6 mm de comprimento por 2-4,4 mm de diâmetro), reunidas em fascículos axilares de até 6 flores nos ramos jovens, sobretudo nos angulosos (Figura 1b,d,f). Pedicelos de 1-4 mm de comprimento. Receptáculo floral curto e obcônico, mais largo que alto, medindo 0,4-1,4mm de altura (Figura 1d). Lacínias deltóides, carnosas, geralmente abertas, calosas no ápice e com nervura longitudinal-ventral espessa, de 0,8-1,5 mm de altura (Figura 1f). Pétalas livres, cuculadas, unguiculadas, de ápice bilobado, inseridas entre o bordo do receptáculo e o disco, menores que as sépalas (cerca de 2/3 da sua altura) e alternas a elas (Figura 1e,f). Disco nectarífero carnoso, espes- 
so, pentagonal ou anelar, na metade superior do tubo, deixando uma depressão no centro, onde se aloja o ovário; margem inteira, geralmente ondulada (Figura 1h,f). Estames livres, opostos às pétalas e presos ao disco; anteras com deiscência longitudinal, dorsifixas; filetes laminares, incurvos (Figura 1d,f). Ovário súpero, napiforme e imerso no disco (embora livre), tricarpelar, trilocular e com um óvulo por lóculo; carpelos unidos; estilete curto, exserto, em geral obscuramente tripartido na metade superior (Figura 1g-j). Fruto do tipo pirênio, glabro, roxoenegrecido quando maduro, de 3-6 mm de comprimento por 3-9 mm de largura, obovado a subgloboso (ligeiramente achatado) em vista lateral, arredondado ou trilobado em vista frontal, contendo três sementes (Figura 1c).

Etimologia: De origem latina, o nome genérico (Scutia, bacia) refere-se ao modo como o cálice envolve o fruto. $\mathrm{O}$ termo buxifolia alude à semelhança das folhas com as de Buxus sempervirens L., espécie conhecida popularmente como buxo (Johnston \& Soares, 1972).

Floração e frutificação: Floresce o ano inteiro, mas principalmente entre setembro e janeiro; frutifica de outubro a maio.

Pontos de ocorrência: Distribuída por todas as regiões do Estado, é especialmente freqüente na Campanha, Depressão Central e Serra do Sudeste.

Material examinado: BRASIL: RIO GRANDEDO SUL: Alegrete, Ibirocai, inventário de nativas (am. 14), com flores, J. N. C. Marchiori s.n., 26.XI.1981 (HDCF 931); rio Inhanduí, inventário de nativas (am. 5), com flores e frutos, J.N.C. Marchiori s.n., 24.XI.1981 (HDCF 913). Arroio Grande, Pontal, p. ao farol Ponta Alegre (Lagoa Mirim), arvoreta ca. de 6m, em capão p. à lagoa, flores verdes, J.A. Jarenkow s.n., 04.X.1997 (PEL 18319). Bagé, Casa-de-Pedra, M. G. Rossoni 321, 15.XII.1989 (ICN 87382); ibidem, Casa-de-Pedra, flores amarelo-esverdeadas, M. G. Rossoni 227, 3.XI.1989 (ICN 87385). Barra do Quaraí, arvoreta ca. 3m, em espinal, estéril, J. L. Waechter 2049, 18.XI.1984 (ICN 61620). Bom Jesus, Arr. Cap. Grande, in silvula, B. Rambo s.n., 15.I.1942 (PACA 8824); Passo da Guarda, in araucarieto, ster., B. Rambo s.n., 14.I.1952 (PACA 51832). Caçapava do Sul, para faz. do senhor Ricardo Dotto, em campo úmido na beira da estrada, frutos imaturos, N.R. Bastos 387, 6.XII.1993 (PACA 86858); Passo do Camaquã, CBC, estéril, A. A. Filho \& R. Cauduro s.n., 9.XII.1989 (SMBD 2827). Canguçu, estrada Encruzilhada-Canguçu, coxilha da Boa Vista, N. Martins s.n., 15.I.1974(ICN 27189); estrada CanguçuPiratini, L. Arzivenco s.n., 15.XI.1975 (ICN 48564); estrada de Canguçu para Pinheiro Machado, $15 \mathrm{Km}$ após Cancelão, árvore isolada no campo, ca. 4m, S. Miotto 566, 9.X.1977 (ICN 35326); ibidem, M. Fleig 776, 9.X.1977 (ICN 51524). Camaquã, Pacheca, mata de galeria do rio Camaquã, arvoreta ca. de $4 \mathrm{~m}$, em borda de mata de galeria, flores verdes, J.A. Jarenkow s.n., 31.X.1989 (PEL 11522). Cambará do Sul, p. São Francisco de Paula, ad araucarietum in umbrosis repens, ster., B. Rambo s.n., II.1948 (PACA 36360). Canela, Caracol, in araucarieto, fl., K. Emrich s.n., 26.II.1946 (PACA 33297); ibidem, Caracol, 8Km N Canela, Parque Estadual, M. L. Porto et alii s.n., 2.I.1973 (ICN 28498); ibidem, 8Km N Canela, Parque Estadual, P. Pellizarro s.n., 27.XII.1972 (ICN 28496). Caxias do Sul, Vila Oliva, in araucarieto humido, fl., B. Rambo s.n., 31.I.1946 (PACA 30830); ibidem, in silvula campestri, fl., B. Rambo s.n., 17.VII.1954 (PACA 55862); ibidem, in silvula campestri, B. Rambo 30830 , 6.I.1946 (ICN s.n.). Encruzilhada do Sul, Passo do Marinheiro, a $30 \mathrm{Km}$ de Santana da Boa Vista, em encosta de cerro, solo arenoso, árvore ca. de $3 \mathrm{~m}$, fr., N. R. Bastos 119 \& S. Diesel s.n., 18.IV.1991 (PACA 70767); estrada para São José, Km 7, N. Martins s.n., 27.VI.1975 (ICN29276); estrada EncruzilhadaCanguçu, coxilha da Boa Vista, N. Martins s.n., 15.I.1974 (ICN 27189). Esmeralda, Est. Ecológica de Aracuri, árvore do sub-bosque do pinhal, flores verde-claras, J. L. Waechter 1853, 8.XI.1981 (ICN 51072); ibidem, arbusto ca. $3,5 \mathrm{~m}$, em interior de mata com Araucária, J. A. Jarenkow 45, 8.XI.1982 (ICN 59120); ibidem, em interior de mata com Araucária, arbusto ca. 4m, J. A. Jarenkow 7, 28.III.1982 (ICN 59094); em interior de mata, arvoreta ca. $3 \mathrm{~m}$, flores brancas, frutos imaturos, M. Sobral et alii 3019, VIII.1984 (ICN 61817). Esteio, p. Porto Alegre, in silvula paludosa, fl., B. Rambo s.n., 2.XI.1932 (PACA 1843). Gravataí, p. Porto Alegre, in silvula riparia, ad fl., B. Rambo s.n., 11.I.1949 (PACA 44337). Jari, p.Tupanciretã, in silvula humida, ster., B. Rambo s.n., 26.I.1942 (PACA 9361). Julio de Castilhos, Val de Serra, com flores e frutos, E. J. Santini s.n., 1.XI.1981 (HDCF 1093); ibidem, 

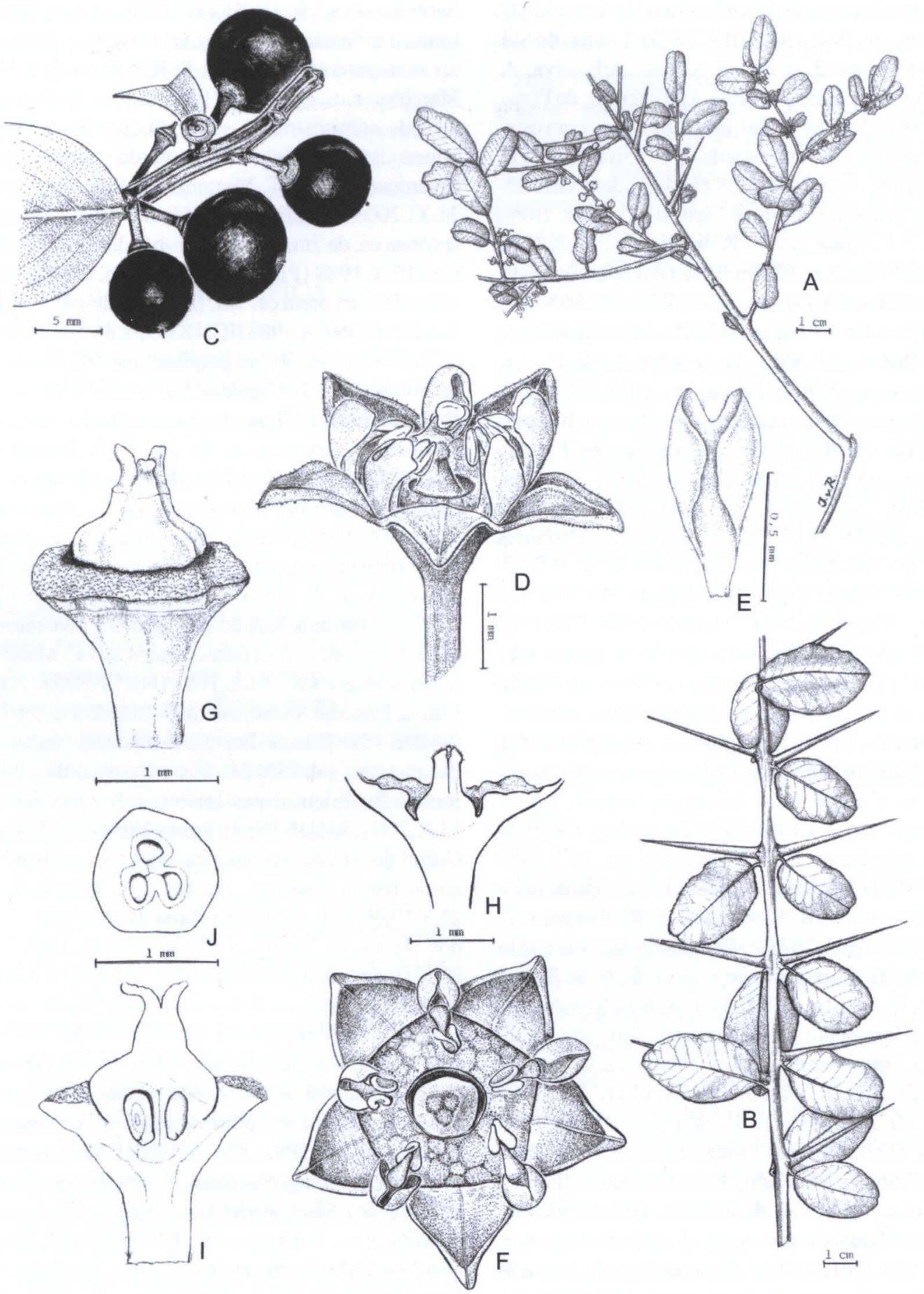

$\stackrel{1 \mathrm{~cm}}{\longmapsto}$

FIGURA 1 - Aspectos gerais de Scutia buxifolia. A - Flores reunidas em fascículos, em pequenos ramos axilares inermes. B - Ramo longo, com espinhos vigorosos e folhas pequenas subopostas, de ápice retuso. C - Ramo curto, anguloso e inerme, com frutos. D - Flor em vista lateral. E - Pétala. F - Flor em vista frontal, mostrando disco nectarífero com depressão central e estames incurvos. G - Gineceu. H - Corte longitudinal do disco nectarífero. I - Corte longitudinal do gineceu. J - Corte transversal do ovário. (Fonte: Flora Ilustrada de Entre Ríos. IV). 
com flores, inventário de nativas (am. 31/134), J.N.C. Marchiori s.n., 29.X.1981 (HDCF 892). Lavras do Sul, faz. Aldo Abascal, arbor in pascuis, arbustiva, A. Sehnem 11866, 11.II.1971 (PACA69792); faz. do Pôsto, $12 \mathrm{Km}$ W de Lavras do Sul, arbusto ca. 4m, com espinhos, flor amarelo-esverdeada, J. C. Lindeman \& B. E. Irgang s.n., 16.X.1971 (ICN 8634); ibidem, em campo com grupo de arbustos, arbusto ca. $3 \mathrm{~m}$, flores verdes, J. C. Lindeman \& B. Irgang s.n., 16.X.1971 (ICN8607); ibidem, 12 Km W de Lavras do Sul, J. C. Lindeman \& B. Irgang s.n., 16.X.1971 (ICN 8634); 15 Km NE Lavras do sul, em restinho de mata, arbusto ca. $3 \mathrm{~m}$, flor esverdeada, fruto azul-arroxeado-escuro, J. C. Lindeman \& B. E. Irgang s.n., 17.X.1971 (ICN 8734). Santana do Livramento, Cerro Armour, B. Irgang s.n., 26.III.1976(ICN 32379). Muitos Capões, Planalto das Araucárias, em capão com Araucária, arvoreta, N. R. Bastos s.n., 14.IX.1997 (PACA 84924); N. R. Bastos et alii 460, 14.IX.1997 (PACA 92027). Palmares do Sul, faz. das Almas, in silvula humida, fl., P. Buck s.n., I.1945 (PACA 26385). Passo Fundo, FLONA, com flores, S.J. Longhi \& J.N.C. Marchiori 538, 5.XI.1985 (HDCF 1867). Pelotas, s.l., Irmão Augusto s.n., 26.I.1941 (ICN 19708); na praça em frente ao estádio Boca-do-Lobo, arvoreta ca. 6-7m, frutos marromavermelhados, J. N. C. Marchirori s.n., 4.V.2007 (HDCF 5730). Pinheiro Machado, Pedras Altas, freqüente em capoeiras e matas ralas da região, estéril, J.N.C. Marchiori s.n., 25.I.1984 (HDCF); ibidem, Cerro da Guarda, com frutos, J. N. C. Marchiori s.n., 15.V.1984 (HDCF 1531). Piratini, Cancelão, em campo na beira da estrada, fr., N. R. Bastos 103 \& R. Wasum s.n., 9.IV.1991 (PACA 70732); faz. São João, sobre solo arenoso com afloramento de granito, fr., N. R. Bastos 112 \& R. Wasum s.n., 8.IV.1991 (PACA 70725); ibidem, junto a afloramento de rochas graníticas em campo, p. à casa, agrupamento de 3-4 árvores, ca. de 4m, fr., N. R. Bastos 111, R. Wasum \& S. Diesel s.n., 8.IV.1991 (PACA 70726); fértil, R. Záchia 3297, 19.III.1999 (SMDB 7039); Serra das Asperezas, BR-293, p. à divisa com Pinheiro Machado, árvore ca. de $4 \mathrm{~m}$, junto a pequeno agrupamento de árvores, em encosta pedregosa, flores esverdeadas, J.A. Jarenkow s.n, 19.XI.1989 (PEL 11605). Quaraí, faz. do Jarau, in silvula humida, ster., B. Rambo s.n., I.1945 (PACA 26363). Rio Grande, Estação Ecológica do Taim, árvore pequena, ca. de $5 \mathrm{~m}$, em beira de mata arenosa, flores verde-amareladas, J.L. Waechter s.n., 08.XI.1986 (PEL 9611); ibidem, arvoreta ca. de 4m, no capão em frente à sede, s. leg., 02.XI.1985 (PEL s.n.); ibidem, em frente a sede administrativa, arbusto ca. 3-3,5m, frutos marrom-avermelhados, S. R. Santos \& J. N. C. Marchiori s.n., 3.V.2007 (HDCF 5729); ibidem, atrás da sede administrativa, arvoreta com 5-6m, tronco pouco desenvolvido, folhas verde-escuras, flores esverdeadas, J. N. C. Marchiori \& S. R. Santos s.n., 24.XI.2006 (HDCF 5722); ibidem, mata do Albardão, arvoreta ca. de $7 \mathrm{~m}$, flores verde-pálidas, J.L.Waechter s.n., 16.X.1988 (PEL 10879); ibidem, em campo no Albardão, arvoreta ca. $7 \mathrm{~m}$, flores verde-pálidas, J. L. Waechter 2360, X.1988 (ICN 83693); ibidem, em beira de mata arenosa, árvore pequena, ca. $5 \mathrm{~m}$, flores verde-amareladas, J. Waechter 2241, s.d. (ICN 81271). Rosário do Sul, Vacaquá, em encosta de cerro, solo rochoso, fl., arvoreta ca. de 3m, L. S. Duarte s.n., 9.X.1988 (PACA 69625); ibidem, Estância dos Camaquãs, em beira de capão, N. R. Bastos s.n., 4.XII.1989 (PACA 70133); Serra do Caverá, em matinho sobre rocha de encosta, arvoreta com espinhos, frutos verdes, M. L. Porto et alii 2177, 29.V.1976 (ICN 31232). Santiago, Rincão dos Cardoso, inventário de nativas (am. 4/sn), com flores e frutos, J.N.C. Marchiori \& S.J. Longhi s.n., 13.X.1981 (HDCF 825). Santa Maria, Passo do Arenal, estéril, R. Beltrão s.n., 9.I.1953 (SMDB 758); Estação Experimental de Silvicultura, R. Beltrão s.n., s.d. (SMDB 904); Campus da UFSM, Jardim Botânico, flores imaturas, E. Gressler s.n., 13.X.2000 (SMDB 8884). Santa Vitória do Palmar, Curral do Arroio, arvoreta ca. de 4,5m, em borda de mata, frutos imaturos, verdes, J.A. Jarenkow s.n, 25.V.1989 (PEL 11432). Santana da Boa Vista, Passo dos Neves, B. Irgang et alli s.n., 27.IX.1985 (ICN 66271); em mata com Araucária, na beira da estrada, BR-392, arvoreta ca. 2,5m, com frutos, madeira coletada, J. N. C. Marchiori s.n., 4.V.2007 (HDCF 5731). São Borja, Estância Bonita, Mato das Guajuviras, margem adentro, árvores ou arvoretas, com ou sem espinhos, com flores e frutos elípticos carnosos, R. Záchia s.n., 4.X.1993 (PACA 74202). São Francisco de Paula, Floresta Nacional, T. Gracia s.n., II.1977 (ICN 32946). São Gabriel, faz. Santa Cecília, in silvula humida, ster., B. Rambo s.n., I.1944 (PACA 25640). São Martinho da Serra, Rincão dos Trindade, com frutos imaturos, N. S. Calgaroto s.n., 16.IV.2005 (SMDB 9872). São Pedro do Sul, São Lucas, mata do rio Ibicuí, árvore ca. de 5m, flores amareladas e frutos atropurpúreos, R. Záchia, S. Martins \& W. Abreu 3128, 13.XI.1998 (SMDB 6916). São Vicente do Sul, 
mata ciliar do rio Ibicuí, estéril, J.N.C. Marchiori s.n., 17.IV.1981 (HDCF 176). Tupanciretã, in silvula campestri, ster., B. Rambo s.n., 28.I.1942 (PACA 9576). Uruguaiana, com frutos, G. D. Zanetti s.n., II.1996 (SMDB 6441). Vacaria, Capão da Caveira, em mata com Araucária, R. Záchia 1127, 18.VI.1992 (PACA 72162); faz. da Ronda, in silvula humida, ster., B. Rambo s.n.., 10.I.1947 (PACA35013).

\section{DESCRIÇÃO MICROSCÓPICA DO LENHO}

Anéis de crescimento visíveis, marcados por estreita faixa de células parenquimáticas no limite do anel de crescimento. Porosidade difusa (Figura 3A).

Poros numerosíssimos a extremamente numerosos $\left(50-82-162 / \mathrm{mm}^{2}\right)$, ocupando $16,2 \%$ do volume da madeira; solitários e em múltiplos radiais de 3 a 8 células. Poros de seção oval, muito pequenos a pequenos $(27,5-50-75 \mu \mathrm{m})$, de paredes espessas $(2,5-4,8-6,2 \mu \mathrm{m})$ e com abundante conteúdo no cerne. Elementos vasculares muito curtos a curtos $(210-298-400 \mu \mathrm{m})$, com placas de perfuração simples, espessamentos espiralados conspícuos e apêndices geralmente curtos, em uma ou ambas as extremidades. Pontoações intervasculares alternas, ovais a poligonais, muito pequenas $(3-3,6-4 \mu \mathrm{m})$; pontoações raio-vasculares (3-3,4-5 $\mu \mathrm{m})$ e parênquimo-vasculares (3-4-6 $\mu \mathrm{m})$, pequenas e arredondadas, semelhantes às intervasculares (Figura 3A,B,D,F).

Parênquima axial paratraqueal escasso e apotraqueal marginal, ocupando $13,6 \%$ do volume da madeira; composto de séries verticais não estratificadas, medindo 147,5-266-353 $\mu \mathrm{m}$ de altura, com 3-4-8 células; células parenquimáticas axiais retangulares, de 32,5-59$143 \mu \mathrm{m}$ de altura por $10-15,7-25 \mu \mathrm{m}$ de largura (Figura 3B,D,E).

Raios muito numerosos (15-21-29/mm), ocupando $32 \%$ do volume da madeira. Tecido radial heterogêneo tipo II, composto de células curtamente procumbentes e células quadradas, na parte multisseriada, e células eretas e quadradas, na margem. Raios unisseriados nume- rosos ( $28,2 \%$ do total), extremamente baixos a muito baixos (67,5-239-960 $\mu \mathrm{m})$, com 2-8-33 células e extremamente finos (7,5-10,4-15 $\mu \mathrm{m})$. Raios multisseriados, em sua maioria tetrasseriados $(26,5 \%)$ ou com mais de quatro células de largura $(23 \%)$, menos comumente bisseriados $(13,3 \%)$ e trisseriados $(9 \%)$; variam de muito baixos até altos (122-569-1187 $\mu \mathrm{m})$, com 4-27-59 células de altura, e de muito finos a finos (15-36-52 $\mu \mathrm{m})$, com até 6 células de largura. Raios de relacionamento normal, por vezes axialmente fusionados; raios agregados, ausentes. Células envolventes, esclerosadas, latericuliformes, mucilaginosas e oleíferas, ausentes; cristais prismáticos de oxalato de cálcio, abundantes em células radiais (Figura 3B,C,E,F).

Fibras ocupando 38,2\% do volume da madeira; fibras libriformes muito curtas (390-799$110 \mu \mathrm{m})$, estreitas $(10-13,7-17,5 \mu \mathrm{m})$ e de paredes muito espessas (3,7-4,7-6,2 $\mu \mathrm{m})$. Fibras septadas e fibras gelatinosas, ausentes (Figura 3B,F).

Outros caracteres: canais secretores, tubos laticíferos e taniníferos, líber incluso e estratificação, ausentes; máculas medulares presentes.

\section{ANÁLISE DA ESTRUTURA ANATÔMICA}

As principais características anatômicas da madeira de Scutia buxifolia concordam com as referências de Metcalfe e Chalk (1972) para a família Rhamnaceae e gênero Scutia, incluindo: elementos vasculares curtos e estreitos, com placas de perfuração simples, espessamentos espiralados e pontoações intervasculares alternas, muito pequenas; parênquima axial em faixas marginais estreitas; raios baixos, com abundantes cristais; e fibras de pontoações simples, com paredes muito espessas. A freqüência média de raios, observada no material em estudo (21/mm), mostra-se consideravelmente maior do que o referido pelos mesmos autores $(4-10 / \mathrm{mm})$. Aspecto importante na morfologia dos vasos, a presença de apêndices em elementos vasculares constitui novidade para o gênero Scutia. 


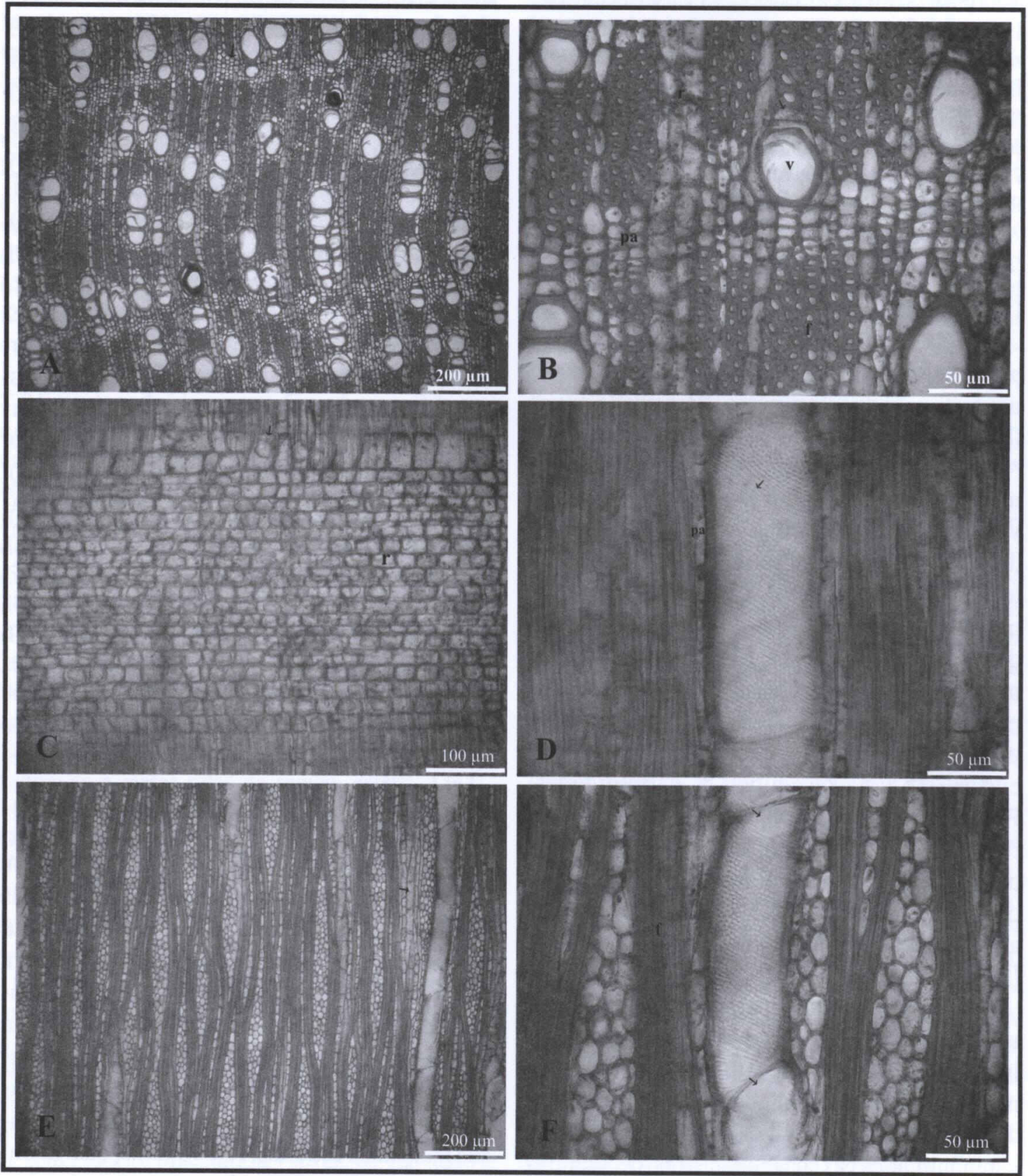

FIGURA 3 - Aspectos anatômicos da madeira de Scutia buxifolia Reissek. A - Porosidade difusa, poros solitários e em múltiplos radiais, com conteúdos (v), e limite de anel de crescimento marcado por parênquima marginal (seta), em plano transversal. B - Os mesmos aspectos em maior aumento, mostrando poros de forma oval (v), parênquima paratraqueal escasso (seta), parênquima apotraqueal marginal (pa), raio (r) e fibras de paredes muito espessas (f). C - Raio heterogêneo, com corpo de células curtamente procumbentes e quadradas (r) e abundantes cristais prismáticos de oxalato de cálcio (seta), em seção longitudinal radial. D - Vasos com espessamentos espiralados (seta), pontoações intervasculares muito pequenas e parênquima paratraqueal (pa), em plano radial; E - Raios muito numerosos, com 1-6 células de largura e 4-59 células de altura; raios unisseriados abundantes e parênquima axial seriado (seta), em plano longitudinal tangencial. F Placas de perfuração simples (seta), raios e fibras, em plano tangencial. 
A presença de elementos vasculares curtos e estreitos, embora possa estar relacionada ao grupo taxonômico a que pertence a espécie, visto que sua ocorrência é comum na maioria dos gêneros da família, também pode ser atribuída à especialização xeromórfica. Marchiori \& Oliveira-Deble (2007), entre outros autores, explicam que o valor adaptativo da presença de elementos vasculares curtos decorre do aumento do número de placas de perfuração por unidade de volume de madeira, o que favorece a capilaridade no xilema. $\mathrm{O}$ aumento da segurança devido a presença de vasos estreitos resulta, pelo menos em parte, da relação inversa que os mesmos mantém com a freqüência de poros: poros estreitos geralmente ocorrem em grande número, aumentando assim a capilaridade por unidade de volume da madeira.

A elevada frequiência de poros e seu agrupamento em múltiplos são características igualmente reconhecidas como estratégias adaptativas em espécies sujeitas a estresse hídrico, por assegurar a continuidade do fluxo de água através de vasos adjacentes, no caso de embolismos locais (Lindorf, 1994).

Embora observado em muitos gêneros de Rhamnaceae (Metcalfe \& Chalk, 1972; Record, 1939), a presença de espessamentos espiralados pode estar mais relacionada à especialização na estrutura anatômica da espécie, decorrente de condições xéricas no passado, do que ao grupo taxonômico em questão. A elevada percentagem de espécies com espessamentos espiralados na parede de vasos em regiões áridas, contribui favoravelmente a esta interpretação (Webber, 1936; Carlquist, 1966; 1975).

Segundo Metcalfe \& Chalk (1972), placas de perfuração simples são de ocorrência generalizada nas Rhamnaceae, sugerindo ser esta uma característica conservativa da família, não vinculada a condições ambientais. Todavia, em certos casos, a presença da mesma pode representar vantagens adaptativas, uma vez que a ausência de paredes transversais nos vasos possibilita maior fluxo de seiva: é o caso, por exemplo, de ambientes secos e quentes, onde se de- senvolvem altas taxas transpiratórias (Alves \& Angyalossy-Alfonso, 2000). Igualmente vinculada ao grupo taxonômico, a presença de pontoações intervasculares diminutas é caráter importante para a identificação do gênero Scutia. Esta característica, juntamente com a presença de parênquima apotraqueal, são aspectos anatômicos dos mais relevantes para separar o gênero em questão, dos demais de Rhamnaceae.

A presença deste conjunto de características evoluídas na madeira de Scutia buxifolia pode ser indicativo da posição filogenética relativamente mais elevada da família, mas, também, como anteriormente mencionado, pode resultar de especialização acelerada, decorrente de um clima árido no passado. A ocorrência de certos caracteres morfológicos, como presença de espinhos e folhas pequenas e coriáceas, comuns em espécies xerófilas, reforça tal interpretação.

A presença abundante de cristais prismáticos de oxalato de cálcio nos raios de Scutia buxifolia concorda com o referido para o respectivo gênero (Metcalfe \& Chalk, 1972), sendo outro aspecto de valor diagnóstico. Na madeira, foram ainda observadas máculas medulares; a presença deste caráter, todavia, não possui valor taxonômico, visto que sua origem vincula-se a fatores externos, como geadas, fogo e injúrias mecânicas (Denardi, 2004).

A excelente qualidade da madeira de Scutia buxifolia (homogênea, dura, pesada e resistente à deterioração) justifica-se plenamente por sua estrutura anatômica. Como salientado por Esau (1959), a composição do lenho, bem como a estrutura e organização de seus elementos constituintes, são fatores determinantes para as propriedades físicas da madeira e sua aptidão para determinados usos. A presença de fibras com paredes muito espessas, ainda que em volume baixo, e de poros de diâmetro pequeno e paredes espessas, tornam a estrutura anatômica mais dura e pesada. De acordo com Burger \& Richter (1991), a presença de abundantes conteúdos no cerne, aliada a estas características, 
confere grande durabilidade natural ao lenho, sobretudo ao cerne, seja por dificultar a penetração de agentes bióticos (principalmente fungos, insetos e bactérias) causadores de apodrecimento e deterioração, seja por tornar a madeira tóxica ou pouco palatável aos mesmos. A ocorrência de porosidade difusa contribui para a homogeneidade da madeira, uma vez que os poros encontram-se uniformemente distribuídos no anel de crescimento. Por outro lado, a presença de raios largos e abundantes pode explicar a tendência natural da madeira em racharse com a secagem, por tratar-se de tecido frágil, menos lignificado.

\section{REFERÊNCIAS BIBLIOGRÁFICAS}

ALVES, E. S.; ANGYALOSSY-ALFONSO, V. Ecological trends in the wood anatomy of some brazilian species: growth rings and vessels. IAWA Bulletin, v. 21, p. 3-30, 2000.

BASTOS, N. R. A familia Rhamnaceae R. Br. no RS: gêneros Condalia Cav. e Scutia Comm. Pesquisas, Botânica, São Leopoldo, n. 40, p. 69-84, 1989.

BURGER, L. M.; RICHTER, H. G. Anatomia da Madeira. São Paulo: Ed. Nobel, 1991. 154p.

BURKART, A.; BACIGALUPO, N. M. Flora Ilustrada de Entre Rios. Buenos Aires: INTA, 2005. $627 \mathrm{p}$.

CARLQUIST, S. Wood anatomy of Compositae: a summary with comments on factors controlling wood evolution. Aliso, v. 6, n. 2, p.25-44, 1966.

CARLQUIST, S. Ecological strategies of xylem evolution. Berkeley: University of California Press, 1975. 259p.

COPANT - Comissão Panamericana de Normas Técnicas: Descrição macroscópica, microscópica e geral da madeira - esquema I de recomendação. Colômbia, v. 30, p. 1-19, 1973.

CORRÊA, P. Dicionário das plantas úteis do Brasil e das exóticas cultivadas. Rio de Janeiro: Imprensa Nacional, 1926. v. 1-6.

DENARDI, L. Estudo anatômico do lenho e morfologia foliar de Blepharocalyx salicifolius (H. B. K.) Berg. em duas regiões do RS. 2004. 94f. Dissertação (Mestrado em Engenharia Florestal) - Universidade Federal de Santa Maria, Santa Maria, 2004.
DUJARDIN, E. P. Eine neue Holz-Zellulosenfaerbung. Mikrokosmos, n. 53, p. 94, 1964.

ESAU, E. Anatomia vegetal. Barcelona: Omega, 1959. 729 p.

JOHNSTON, M. C.; SOARES, M. A. F. Ramnáceas. In: Reitz, R. Flora Ilustrada Catarinense. Itajaí: Herbário Barbosa Rodrigues, 1972. 50p.

KRAUS, J. E.; ARDUIN, M. Manual Básico de Métodos em Morfologia Vegetal. Rio de Janeiro: EDUR, 1997. 198p.

LINDORF, H. Eco-anatomical wood features of species from a very dry tropical forest. IAWA Bulletin, v. 15, p. 361-376, 1994.

MARCHIORI, J. N. C.; OLIVEIRA-DEBLE,A. S. Anatomia da madeira da subtribo Baccharinae Less.: tendências ecológicas de ordem taxonômica e ecológica. Balduinia, n. 11, p. 9-15, 2007.

MARCHIORI, J. N. C. Estudo anatômico do xilema secundário de algumas espécies dos gêneros Acacia e Mimosa, nativas no Estado do Rio Grande do Sul. 1980. 186f. Dissertação (Mestrado em Engenharia Florestal) - Universidade Federal do Paraná, Curitiba, 1980.

MARZOCCA, A.; MARTHI, C. E. M. Las plantas cultivadas en la República Argentina. Buenos Aires: Ministerio de Agricultura y Ganaderia, 1951.48p.

METCALFE, C. R.; CHALK, L. Anatomy of the Dicotyledons. Oxford: Clarendon Press, 1972. $1500 \mathrm{p}$.

RADFORD, A. E; DICKISON, W. C.; MASSEY, J. R.; BELL, C. R. Vascular Plant Systematics. New York: Harper \& Row, 1974. 891p.

RECORD, S. J. American woods of the family Rhamnaceae. Tropical Woods, n. 58, p. 6-24, 1939. RECORD, S. J.; HESS R. W. Timbers of the New World. New Haven: Yale University Press, 1949. 640p.

TORTOSA, R. D. Flora Fanerogámica Argentina: Rhamnaceae. Córdoba: Programa Proflora (CONICET), Museu Botánico, 1995. fasc. 9. 18p.

WEBBER, I. E. The woods of sclerophyllous and desert shrubs and desert plants of California. American Journal of Botany, v. 23, p. 181-188, 1936. 